\title{
Potential Harm in Treatment Failure; Case Study in RSUD Haji Makassar
}

\author{
Rini Anggraeni ${ }^{1}$, Adinda Pramitha Suleman ${ }^{2}$ \\ \{riniacho@gmail.com ${ }^{1}$,adindapramitha30@gmail.com ${ }^{2}$ \} \\ Hospital Management Department, FKM Hasanuddin University ${ }^{1,2}$
}

\begin{abstract}
In the process of treatment and treatment, the occurrence of medication error is a mistake that can lead to treatment failure and has potential harm to the patient. Medication errors include prescribing errors, dispensing errors, and administration errors. The medication error in the Pharmacy Installation of Haji Hospital in the case of medication errors is a problem in the service and does not meet the Minimum Service Standards in the Hospital. This study aims to get an overview of the incidence of medication errors in Haji Hospital in 2017. The research method used in this study is a qualitative research method with a phenomenological approach. Determination of informants using purposive sampling method and obtained by informants as many as ten people. Data collection in the form of in-depth interviews, document review, and observation. The results of the study showed that prescribing errors that occurred in Haji Hospital include doctors who wrote incorrect prescriptions, exchanged prescriptions, doctor's writings were not clear, and recipes were incomplete. Dispensing errors include misreading the recipe, wrong patient, incorrect etiquette, and incomplete medication. Administration errors include not on time, improper way of taking medication, improper patient, and improper medication. The conclusion of the study that medication errors include prescribing errors, dispensing errors, and administration has occurred in Haji Hospital.
\end{abstract}

Keywords: Medication error, prescribing error, dispensing error, and Administration error

\section{Introduction}

Patient safety is a system to make patients safer for medical care, including risk assessment, identification and management of patient risks, reporting and incident analysis, learning ability from incidents and follow-up and implementation of solutions to minimize risk and prevent an injury caused by an error resulting from carrying out an action or not taking the action that should have been carried out [1].

Medical error issues and patient safety attracted the attention of the health world since the Institute of Medicine (IOM) report entitled "To Err is a Human Building A Safer Health System". In the report, 44,000-98,000 people died in the hospital in one year due to medical errors which could have been prevented. This quantity exceeds deaths due to motor vehicle accidents, breast cancer, and AIDS [1].

Medical error issues and patient safety attracted the attention of the health world since the Institute of Medicine (IOM) report entitled "To Err is a Human Building A Safer Health System". In the report, 44,000-98,000 people died in the hospital in one year due to medical 
errors which could have been prevented. This quantity exceeds deaths due to motor vehicle accidents, breast cancer, and AIDS [2].

Drug errors occur in the process of drug use, including prescribing, transcribing, dispensing, and administration, dispensing ranked first. [3] According to Cohen, repeated errors in treatment occur in prescribing, dispensing, and administration [4].

The Joint Commission International (JCI) \& the World Health Organization (WHO) report some countries as much as $70 \%$ of the incidence of medication errors and to cause permanent disability in patients. [5] Based on research conducted by Oumer Sada et al., Stated that prescribing errors in units intensive care of Tikur Anbessa Special Hospital, Addis Ababa, Ethiopia, among others, negligence 154 (42.89\%), one combination of $101(28.13 \%)$, the wrong abbreviation $48(13.37 \%)$, wrong dose $30(8,36 \%)$, wrong frequency $18(5.01 \%)$ and incorrect indication $8(2.23 \%)[6]$.

Based on the National Map Report on Patient Safety Incidents PERSI Congress (2007) in the MOH RI in 2008, errors in drug administration were ranked first $(24.8 \%)$ of the top 10 reported incidents. [1] In the Hospital Patient Safety Guide, reporting the most common patient safety incidents in Indonesia is medication errors, which often become lawsuits and end in cour [7]. Based on standards Minimum services at the Hospital in 2012, there should be no occurrence of medication errors in hospitals, especially in pharmacy installations [8]. From the reporting data of the Pharmacy Installation of the Hajj Regional General Hospital (RSUD), there was an error in giving medication in 2013-2016. In 2013 there was a 27\% error in drug delivery, in 2014 it was $27 \%$, in 2015 it was $13 \%$, and in 2016 it was $33 \%$. Errors in administering this drug cause an incidence of near-injury (KNC) of $87 \%$ and a non-injury event (KTC) of $13 \%$. Errors in drug administration include the wrong patient $(13 \%)$, wrong medication (67\%), wrong dose (13\%), and expired medication (7\%) [9].

Drug errors in the Hajj Hospital Pharmacy Installation occur at the stage of prescribing, dispensing, and administration. Based on research conducted by Fithriyani stated that the occurrence of medication errors in the Pharmacy Installation of Haji General Hospital in South Sulawesi Province was 57 cases. The medication error is caused by prescribing errors of $9 \%$ ( 5 events), dispensing errors (error in drug preparation) of $14 \%$ ( 8 events), and administration errors (medication errors) of $77 \%$ (44 events). [10] Therefore, researchers are interested in examining medication errors in Haji Hospital.

\section{Method}

The research method used in this study is a qualitative research method with a phenomenological approach. This research was conducted in Haji Hospital in Makassar City from April to May 2017. Informants were selected by purposive sampling by adjusting to the research objectives. In this study, researchers managed to obtain informants with a total of ten informants. The informant consisted of three doctors, four pharmacy officers, and three nurses.

Data collection in this study was carried out with 3 methods: in-depth interviews, observation, and review of documents supplemented by interview guidelines, observation sheets, documentation tools (sound and camera recording devices), and field notes. To increase the validity of the data and the credibility of the data (trust) obtained by the researcher, the triangulation method is used, which consists of source and method triangulation. Data processing and analysis used in this study is content analysis or content 
analysis. This analysis is a technique used to analyze and understand the contents of the information. The collected data is interpreted and presented in the form of a draft research report as the research report.

\section{Result}

This research is about the occurrence of medication errors in Haji Hospital, which includes prescribing errors, dispensing errors, and administration errors. In this study, researchers managed to obtain informants with a total of ten informants. The informant consisted of three doctors, four pharmacy officers, and three nurses. Based on interviews about the form of prescribing errors that have occurred in Haji Hospital South Sulawesi Province, obtained information, namely:

"It is not wrong, never wrote a prescription, whichever happened was exchanged. It's not wrong, if it's wrong to correct it quickly, we quickly realize oh wrong, replace it, for example, but if the wrong dose is wrong or not. What happened was exchanged, exchanged for someone else who took it, for example, whose name was, then I wrote who kept taking other things, just exchanged it. Often first, not often 2-3 times.

(RM, 59 years)

"Yes, I have. In the form of prescribing drugs, injecting drugs, only then did I want to write the static that came from Scopamin. Uh, wrong, I want to write scopolamine which comes static but that means there is no bad effect on the patient. No, because it was confirmed by the nurse. The nurse first saw before entering medicine. Tell me how come the docks come different, then I confirm that I wrote the wrong one, then changed it before I put the medicine in ".

(RR, 35 years)

"Alhamdulillah, no one, alhamdulillah is complete, most complaints or phone calls from the pharmacy regarding less clear writing".

(NH, 35 years)

"When hajj has been done for a long time, the doctor first, the error occurs because, for example, from the doctor himself from the recipe that is unreadable. One of the dosage forms is for example, injection, or this is a tablet, two of them. So that's it, wrong dosage form, wrong dosage. What is meant by the preparation is an example; for example, ketorolac injection, the injection is the available form, sometimes the doctor is wrong. He wants 30 $\mathrm{mg} / \mathrm{ml}$ of ketorolac injection $10 \mathrm{mg} / \mathrm{ml}$ ee error because actually what he wants to give to the patient is $30 \mathrm{ml} / \mathrm{gr}$ but what he wrote is $10 \mathrm{ml} / \mathrm{gr}$, or that means the dose is wrong. Finally, the return to the wrong dose is like that. Most often with the doctor is a wrong dose ".

(DM, 41 years)

Based on the results of in-depth interviews, observations and document review conducted by the researchers it can be seen that the form of prescribing errors that occur in Haji General Hospital include doctors writing incorrect prescriptions, exchanging prescriptions, doctor's writings not clear, and incomplete prescriptions. As for the causes of prescribing errors in Haji Hospital based on in-depth interviews, information is obtained: 
"It is normal to rush too many patients, but all of them must be solved. Yes, workload. "

(NH, 35 years)

"But that was the result of this if the doctor was replaced by his resident because the Haj hospital was a lot of residents. Residents can write prescriptions; it's most often ".

(DM, 41 years)

"The doctor changes the doctor who writes the prescription, the resident is not an expert doctor, the resident from Wahidin from Umi from anywhere he moves from the hospital every resident's day changes, every day the doctor assistant change, who writes the resident's recipe, who writes the doctor assistant recipe so here the officer was so overwhelmed, hurriedly added that his writing was unclear, right?"

(HM, 37 years)

"Usually the doctor is replaced with his resident if the doctor himself knows his writing anyway, is biased".

"Yes, because residents who write prescriptions are not expert doctors."

$(\mathrm{AD}, 35$ years $)$

. (SM, 27 years $)$

Based on the results of in-depth interviews and review of documents in the form of recipes. The researcher can be seen that the cause of prescribing error in Haji Regional Hospital includes the same patient's name, doctor's workload, doctor replaced by resident, bad doctor's writing and similar drug name. As for how to overcome prescribing errors in Haji Hospital based on in-depth interviews, information is generated:

"The solution is to have an address, call the person, return the medicine. Called by his family, if necessary, find the house, take the recipe, take it. "

(RM, 59 years)

"Yes, it was confirmed, so it was repeated, saying that I was the wrong one fortunately not yet given the medicine."

(RR, 35 years)

"Making it like that when we find a recipe that can't be read we have to make sure to go to another pharmacist if our answer is different then we have to call the doctor. So all doctor's telephone numbers must be stored here. Well so also if we find the dose, we see, ohh the dose is over, or the dose is below or more then also we have to contact the doctor so whatever we find there is a good dose, ee eg if this drug should be orally or an example of this drug should, but it turns out the doctor is intravenous. We have to communicate it to the doctor, or this drug should be oral or why the injection, the doctor is sometimes like this writing tablet/injection, but why does the tablet want all ahh injection. So the point is that whatever we find must be directly communicated with the doctor ".

(DM, 41 years)

"If we can confirm it, we usually confirm that the front part is the front sensor part, that's it."

(HM, 37 years)

Based on the results of in-depth interviews, observation and document review conducted by the researcher it can be seen that the way to overcome prescribing errors in Haji Hospital is the patient's or family's telephone and confirmation to the doctor. The dispensing error is an error that occurs in preparing the drug, including the pharmacy officer, is not careful in 
receiving the recipe until drug delivery to patients. Based on interviews about the form of dispensing errors that have occurred in Haji Hospital, the following information is obtained:

"The wrongest is misreading, the pharmacy is wrong to read. That usually sometimes starts from a mistake that is made if a friend is not focused enough, you pay attention to the number again, or the friend who receives the recipe forgets to give the number, now if he forgets the number, then he can finally be wrong, the patient is wrong. So the fatal thing will be done when the delivery is wrong. "

(DM, 41 years)

"Misreading the recipe, misrepresenting the intent is exchanged with a name similar to the same name, so the name is just a poly difference, meaning a different place, check it. There are many here, meaning that there are many kinds of names whose faults are so, yes, most often they are misread here, usually they don't have time to be handed over by officers in the front who can continue or all are right in front of a tired person, right in front of a tired one or misplaced or all right when called the patient's error is that. Then in the etiquette section here it should be said, he will read, he does not use drug control he reads the recipe right so if he has written the etiquette, he stops etiquette right, the medicine is matched right, he is stopped, the medicine is for example amoxicillin he sees ohh the medicine is amoxicillin only he can keep right. Well, except here he wrote wrong, it should be 2x1, but he wrote 1x1 in the front, who knows what to do, that's why the end of it is all in front of the handover. The submission section must be super careful.

(HM, 37 years)

"If it is me that I have experienced, then maybe he is a pharmacist, if I am a pharmacy technical person, then my position is not to be screened for prescriptions at the same time as there is to be a pharmacist. I am prepared for more technical personnel for technical personnel; if we are the most frequent technical personnel, the recipe is often misread the most often because we, if the pharmacy installation looks like there is a division, what is the authority? Also if the technical staff is in the drug preparation section, for the prescription and screening of the prescription at the pharmacist. So, if we ask a question, I find it most often because my position here is that the most frequent mistake is a recipe error.

$(\mathrm{AD}, 35$ years $)$

Based on the results of in-depth interviews conducted by researchers, it can be seen that the form of dispensing errors that have occurred in Haji District Hospital include misreading the prescription, wrong patient, incorrect etiquette and incomplete medication. The cause of error dispensing in Haji Hospital based on in-depth interviews, obtained information, namely:

"The number one cause is not SPO, so that's number one. Well, the first is not compliant with the SPO, both workloads. . . The third is knowledge, meaning that each person has different knowledge, the more often you train, the more often you learn what your name must be. The better your knowledge, the more accurate you are. Yes, the environment, why the environment, for example, in front of us, we receive the recipe coming from behind, hunting down, forcing the medicine to be fast, the environment is very disturbing because we have concentrated in front of receiving patients from behind there are employees, friends or what they want to be served quickly. It is disturbing, breaking concentration, the environment is also bad habits like accepting the phone when working a it is very disturbing to tell stories while working it is likely that there will be an error".

(DM, 41 years) 
"His name is prepared by a man if we are tired, the patient has a few officers, the patient wants to be fast, right, finally it is wrong, it must be wrong. . . His name is the same because in a hurry, he doesn't pay attention to what his name is, or he doesn't pay attention to what his name is, the doctor is right, maybe sometimes we ask again. Obviously, it's just because his patients are already tired of waiting, already tired of waiting finally, yeah. Yes, yeah, right, he just heard the tip or just heard it, yeah. Asked this, yes, asked this, do you know that when you go home, it is matched again with the recipe, right?"

(HM, 37 years)

"Indeed, if you say maybe you are 'tired', pressure, especially what we are shifts if the obstacles are busy are still too many prescription quantities anyway. ... yes, right workload. Yes, external factors are the environment, especially if we are serving that night".

$(\mathrm{AD}, 35$ years $)$

"Officers if for example, there have been many recipe concentrations decreased, especially during the afternoon. Moreover, there have been lots of accumulation, but there should be two people here, but because now the officer is a little, so every day is now 1 person here. It should be here 4, here 1 here is a 3-window counter for patients, what is the 3-window counter for inpatient, outpatient BPJS patients. This is the counter for 1 general patient and $E R$, window 2 for drug delivery. There should be 2 people there 1 here 1, but there are fewer employees, so here all are accepted (window 1) ".

(SM, 27 years)

Based on the results of in-depth interviews, observation and document review conducted by the researcher it can be seen that the cause of error dispensing in Haji Regional Public Hospital includes non-compliance with SPO officers, workload, knowledge and environment/interference. As for how to overcome error dispensing in Haji General Hospital based on in-depth interviews, obtained information, namely:

"Making it like that when we find a recipe that can't be read we have to make sure to go to another pharmacist if our answer is different then we have to call the doctor. Search, yes, look for the address, there must always be recorded in the medical record anyway. So it is also common for the friend to hand over the address medicine which is recorded to be prescribed, it is definitely easy to find, so you have been able to get the address all this time."

(DM, 41 years)

"If it is confirmed, we usually confirm that the front is there, that's the front sensor part of that".

(HM, 37 years)

"It was a reconfirmation to the doctor, what it was on 'hmmm' that was also an obstacle if we confirmed it while the doctor was also not on site anyway. Obstructed, surely hampered, because sometimes we have to wait for the nurse to confirm to us. Most if there is no confirmation to the doctor, then the nurse will contact the doctor, but we have to wait for the nurse again. Waiting, have to wait again. Asked by a mother who brings the patient, what is the name of the patient, but sometimes if we want to take the risk, we will ask again.

(AD, 35 years)

"For example, if there is something you confirmed, first go to the doctor. After that, the recipe was brought back to where the recipe was any way where the treatment was finished 
when it was corrected again the writing was brought here again. Some can be confirmed; some don't. For example, if you lift your cell phone, then if you can't talk to your doctor.

(SM, 27 years)

Based on the results of in-depth interviews, observation, and review of the documents carried out

Researchers can find out how to overcome error dispensing in Haji Hospital is a confirmation to the doctor and look for the patient's address. Administration error is a mistake that occurs in the process of giving the drug to the patient, including the nurse does not apply the principle of giving the drug that is the patient is not right, the drug is not right, the dose is not right, not timely and improper way to consume the drug. Based on interviews about the form of administration errors that have occurred in Haji Hospital, information was obtained, namely:

"It seems rare because there are names, medical records, and birth dates that we refer to and identify them, each patient we wear a bracelet before giving action to the patient. We ask what name is appropriate or not. There has never been a human name. What we usually do is not exactly like taking medicine if the child is sleeping because it is not the same as the schedule.

(SA, 37 years)

"I never have and hopefully not. That was before the bracelet verification process was carried out. False to recognize the drug, wrong schedule for drug administration. The day that happened was wrong in giving, exchanging Cipro with piracetam. The piracetam should have entered at noon; it was entered at 10 o'clock because it was the same bottle as the piracetam with the bottle with Cipro. Yes, it's supposed to be the Cipro at 12 o'clock, piracetam at $10 o^{\prime}$ clock. It's just upside down, exchanged drugs and hours of administration.

(AG, 31 years)

Based on the results of in-depth interviews conducted by researchers, it can be seen that the form of administration errors that have occurred in Haji Hospital are not timely. Improper way of taking medication, improper patient, and improper medication. As for the causes of administration errors in Haji District Hospital based on in-depth interviews, information was obtained, namely:

"It could be because the workload is too tired, but it becomes less focused, but so far it's rare".

(SA, 37 years) "Maybe that is too far if the patient. Power is not comparable to the patients we care for. Yes, the workload is possible.

(SR, 30 years) "Same, similar, LASA. It could also be the burden of life brought from home to work.

(AG, 31 years)

Based on the results of in-depth interviews conducted by researchers, it can be seen that the causes of administration errors in Haji Hospital include workload, no patient identification, and similar forms of medication. As for how to overcome administration errors in Haji Hospital based on in-depth interviews, obtained information:

"We collaborate with the doctor". 
"We keep returning to report the DPJP (Doctor of Patients in Charge). We follow the instructions what next if something like that happens".

(SR, 30 years)

"Reportedly, it happened to be my connecting shift day, before I reported it to the head of the room later the head of the room to the maintenance section, later the nursing department that reported again to the quality department".

(AG, 31 years)

Based on the results of in-depth interviews conducted by researchers, it can be seen that the way to overcome administration errors in Haji Hospital is to report to the headroom and coordination with the doctor.

\section{Discussion}

The prescribing error is a medication prescribed incorrectly or an order given orally or prescribed by an incompetent doctor [1]. The form of prescribing error that occurs in Haji Regional Hospital includes doctors writing incorrect prescriptions, exchanging prescriptions, doctor's writings not clear, and incomplete prescriptions. This is supported by the results of observations and reviews of documents that have been conducted by researchers that there are still many recipes that are not clear in writing and incomplete and there are no operational procedure standards (SPO) regarding prescription writing in Haji Hospital.

Based on observations, the researchers found that incomplete prescriptions included no doctor's name, no patient address, no prescription date (inscription), no medical record number, no patient's birth date, no dosage, no rules drug use, there is no signature or initial prescription doctor, and there is no drug dosage form. This is in line with the research conducted by Susanti, stating that in prescribing potential errors occur, the recipe is illegible $0.3 \%$, the name of the drug is an abbreviation of $12 \%$, there is no administration dose of $39 \%$, there is no amount of administration of $18 \%$, there is no rule of use $34 \%$, not writing unit dose $59 \%$, no dosage form $84 \%$, no route of administration $49 \%$, no date for prescription request $16 \%$, incomplete patient identity (no medical record number $62 \%$, age $87 \%$, body weight $88 \%$, body height $88 \%$, patient sex $76 \%$, and patient room number $77 \%$ ).

The cause of prescribing error in Haji Hospital, including the same patient's name, doctor's workload, doctor replaced by resident, bad doctor's writing, and similar drug name. This is supported by the results of a document review in the form of a recipe that there is a recipe written by the resident and that the doctor's writing is bad/illegible. Besides that, how to overcome prescribing errors in Haji Hospital is the patient's or family's telephone and confirmation to the doctor. The statement from the informant can be supported by the results of observation and review of documents in the form of Standard Operating Procedure (SPO) documents. According to Robert J. Weber and Shawn E. Johnson, errors can occur at every step in the treatment process. Medication error occurs due to a number of reasons, including the name of the drug product (Names and Similar / NORUM Speeches, or Look-Alike Sound-Alike / LASA, lettered or prefixed numbers and suffixes in the name of the drug), unreadable handwriting, no personnel trained enough, the use of abbreviations in prescriptions is not clear and the workload is excessive [12].

Dispensing is a process of preparing and delivering drugs to the recipient of the drug (patient/family of the patient) [13]. The form of dispensing errors that have occurred in Haji Hospital include misreading the prescription, wrong patients, incorrect etiquette, and incomplete medication. This is in line with the research conducted by Fithriyani, stating that 
dispensing error was $14 \%$ (8 events) which included taking the medication incorrectly, writing incorrect etiquette, and incorrect medication dosage [10]. According to the Ministry of Health of the Republic of Indonesia in 2008, other factors contributing to medication errors included communication (miscommunication, failure in the communication), environmental conditions, interruption at work, workload, and staff education [1].

The causes of error dispensing in Haji Regional Public Hospital include non-compliant SPO officers, workload, knowledge, and environment/interference. This is supported by the results of observation and review of documents in the form of Standard Operating Procedures (SPO) documents. Based on the observation and document review, it can be seen that the patient or family often ask at the prescription reception counter so that the pharmacist interrupts the prescription screening, the officer does not comply with the SPO, which is preparing his medication from receiving the prescription until the prescription is given, and there are 3 counters, namely counter 1 for general patients and ER, 2 counters of drug delivery, and 3 counters for BPJS patients hospitalized and BPJS outpatient, which should have 4 officers in the sky but only 2 officers were present. How to deal with error dispensing in Haji Hospital is confirmation to the doctor and look for the patient's address. This is supported by the results of observation and review of documents in the form of standard operating procedure documents (SPO).

Based on observations, it can be seen that the pharmacy officer directly contacted the prescribing doctor when he found the doctor's writing that was not clear. Whereas based on the results of the review of the document in the form of an SPO document about drug preparation it can be seen that if there is any doubt in reading the recipe ask the other officer and if there is any doubt in reading the recipe contact the prescription doctor, and when giving the drug if necessary record the patient's address. Administration error is a mistake that occurs in the process of giving the drug to the patient, including the nurse does not apply the principle of giving the drug that is the patient is not right, the drug is not right, the dose is not right, not timely and improper way to consume the drug. The principle of drug administration is a guideline in giving therapy so that giving errors do not occur, side effects can be prevented or overcome, and unwanted reactions can be overcome [14]. According to Jones \& Bartlett, the principle of 6 giving drugs is correct, that is correct medicine, correct time, correct dose, correct patient, the correct way to consume drugs, correct preparation and administration [15]

The form of administration errors that have occurred in Haji Hospital is not timely. Improper way of taking medication, improper patient, and improper medication. This is in line with research conducted by Krzyzaniak, stating that patient identification errors and overdoses are very common in neonates, with $47 \%$ of administration errors that involve at least ten times overdose [16].

Based on the research conducted by Mohammadi et al., stated that the occurrence of medication errors such as errors in administration time (55.6\%), and administration of drugs without a prescription (44.5\%) [17].

This is supported by the results of observations and document review. Based on observations, it can be seen that nurses pay attention to 7 correct drug administration. Based on the review of the document that in the patient's medical record file there is a document checklist form 7 correct administration of the drug includes the correct patient, correct drug, correct dose, correct route, correct time, true expiration, and correct documentation. Also, in the medical record file, there is a drug administration document which includes the name of the drug, drug dosage, frequency/rules of use of the drug, route, and date of administration of the drug. Based on the review of the document in the form of SPO drug administration, it can 
be seen that before giving the drug the officer first reads the drug according to the patient with the correct principle of the drug, correct patient, correct dose, correct time, and correct route.

The cause of administration errors is workload, no patient identification, and similar forms of medication. According to Smith, factors that cause medication errors are related to compliance with the application of drug delivery standards as follows: drug management procedures (planning, procurement, storage, distribution, prescription services), work environment (physical environment, busy work, and interruptions), the patient health workers (communication, workload, knowledge and work culture) [14]. Besides that, the way to overcome administration errors in Haji Hospital is to report to the head of the room and coordinate with the doctor [18].

\section{Conclusion}

Prescribing errors that occur in Haji Hospital include doctors writing incorrect prescriptions, exchanging prescriptions, doctor's writing is unclear, and incomplete prescriptions. The causes of prescribing errors include the same patient's name, doctor's workload, doctor replaced by resident, bad/illegible doctor's writing, and similar drug name. Dispensing errors that have occurred in Haji District Hospital include misreading the prescription, wrong patient, incorrect etiquette, and incomplete medication. The causes of dispensing errors include the doctor's writing is not clear; SPO non-compliant officers, workload, knowledge, and environment/interference. Administration errors that have occurred in Haji Hospital are not timely. Improper way of taking medication, improper patient, and improper medication. Causes of administration errors include workload, no patient identification, and similar forms of medication. Based on the results of the study it is suggested that the hospital should be able to make prescription standard operating procedures that are good and right so that it can be used as a reference or guide by doctors in prescribing and preventing the occurrence of prescribing errors. Drug preparation process is even better to prevent dispensing errors, nurses should be more obedient in applying the principles of drug administration to prevent administration errors, and the hospital should improve the reporting culture and recording medication errors in the hospital so that it can be used as learning material and future evaluation.

\section{References}

[1] Ministry of Health Republic of Indonesia.: Regulation of the Minister of Health of the Republic of Indonesia Number 1691 / MENKES / PER / VIII / 2011 concerning Hospital Patient Safety. Pp.1-40 (2011)

[2] Timbongol, C., Lolo, W. A., \& Sudewi, S.: Identification of Medication Errors (Prescribing) at the Internal Police of Bitung Hospital. Journal of Scientific Pharmacy Unsrat.Vol.5.pp.1-6 (2016)

[3] MOH RI.: Pharmacist's Responsibility to Patient Safety (Patient Safety). Jakarta: Ministry of Health.pp.32-40 (2008)

[4] Cohen, M. R.: Medication Errors 2th Editions. American Pharmacists Association. Washington DC.pp.23-30 (2007)

[5] Fatimah, F. S.: Overview of the Application of the Right Principle of Drug Giving at PKU Muhammadiyah Yogyakarta Hospital Unit II. Indonesian Nurse and Midwifery Journal. Vol.4.pp.7983 (2016).

[6] Sada, O., Melkie, A., \& Shibeshi, W. Medication Prescribing Errors in The Medical Intensive Care Unit of Tikur Anbessa Specialized Hospital, Addis Ababa, Ethiopia. BMC Research Notes. Vol.8.pp.448 (2015) 
[7] MOH RI. National Guideline for Hospital Patient Safety (Patient Safety). Jakarta: Ministry of Health.pp.40-45 (2008)

[8] MOH RI.; Hospital Minimum Service Standards. Jakarta: Ministry of Health.pp.6-25 (2012)

[9] Haji Hospital, South Sulawesi Province. Book of Pharmacy Installation Report of Provincial Haji Hospital South Sulawesi. Makassar: Haji Hospital, South Sulawesi Province.pp.78-80 (2016)

[10] Fitriyani.: Factors Contributing to Medication Error Events in Haji Hospital Makassar [Thesis]. Makassar: Hasanuddin University.pp.70-76 (2012)

11. Susanti, I.: Identification of Medication Error in the Prescribing, Transcribing, and Dispending Divisions in Pharmacy Deposits for Inpatient Internal Medicine of the Pharmacy Installation of Fatmawati General Hospital 2013 Period [Thesis]. Jakarta: UIN Syarif Hidayatullah Jakarta.pp.67-70 (2013)

12. Mark SM, Little JD, Geller, W. R.: Principles and practices of medication safety. Pharmacotherapy: A Pathophysiologic Approach. Mc Graw-Hill Education.pp.6-10 (2014)

13.Wijaya, S. A.: Medication Error Risk Analysis at Hasanuddin University Hospital [Thesis] Makassar: Universitas Hasanuddin.pp.12-30 (2016)

14.Vania, S. Compliance with the Standard Application of Drug Administration by Pharmacy Staff at Stella Maris Makassar Hospital in 2016 [Thesis]. Makassar: Hasanuddin University.pp.21-30 (2016)

15.Jones, \& Bartlett.: Nurse's Drug Handbook. Jones \& Bartlett Learning. USA.pp.34-50 (2011)

16. Krzyzaniak, N., \& Bajorek, B. Medication Safety in Neonatal Care: A Review of Medication Errors Among Neonates. Therapeutic Advances in Drug Safety.Vol.7.pp.102-119 (2016)

17. Mohammadi, A., Zarea, K., Rasouli, M., \& Haghighizadeh, M. H.: Medication Errors and heir Relationship with Job and Demographic Characteristics Among Nurses in Hospitals of Ahvaz Jundishapur University of Medical Sciences. Jentashapir J Health Resource.Vol.5.pp.141-151.

18. Rosmala Nur, Anwar Mallongi, Indah P. Kiyai Demak, Fadliah, Elli B. Yane, Nurhaya S. Patui, Marselina , H. Muhammad Rusydi, Muhammad Asep Dwitama and R. Erina Thursina.: Early-Age Marriage and the Impact of Health Reproduction Women. Journal of Engineering and Applied Sciences.Vol.14.pp.981-986 (2019) 